\title{
Beifing media join attack on air pollution
}

[BEIJING] China's capital, one of the world's most polluted cities, has begun to clean up its air following moves by a number of cities in China to release data on air pollution levels. Beijing has long suffered from air pollution produced by the burning of low quality coal in homes and factories, and its growing number of cars is aggravating the problem.

Similar problems afflict many Chinese cities. Indeed, a World Bank report last year cited air pollution as one factor making chronic obstructive pulmonary disease emphysema and chronic bronchitis - the leading cause of death in China.

The problems are not confined to China's cities. Acid rain is afflicting forests, particularly in the south. And China is also believed to be a growing source of the acid rain that falls in neighbouring countries, such as Japan (see Nature 392, 426; 1998).

Despite a 1989 law requiring environmental reports by all levels of the Chinese government, local governments have only recently begun to release figures on air pollution. Last year, 27 cities began making weekly air pollution reports, and Beijing's local government started releasing figures on $28 \mathrm{Feb}$ ruary, immediately before the opening of the National People's Congress in March.

The start of weekly reports in Beijing has been followed by intense media coverage of air pollution problems in what Western observers say is an orchestrated effort by the new central government to build public awareness as it starts to tackle the problem.

The former National Environmental Protection Agency has been upgraded to ministerial status in the central government, and renamed the State Environmental Protection Administration. But with only 400 employees it is hard for the new ministry to enforce environmental controls nationwide. Observers say this is why the administration is using the media to bring pressure on local governments.

The amount of information released varies from city to city. In Shanghai, one of

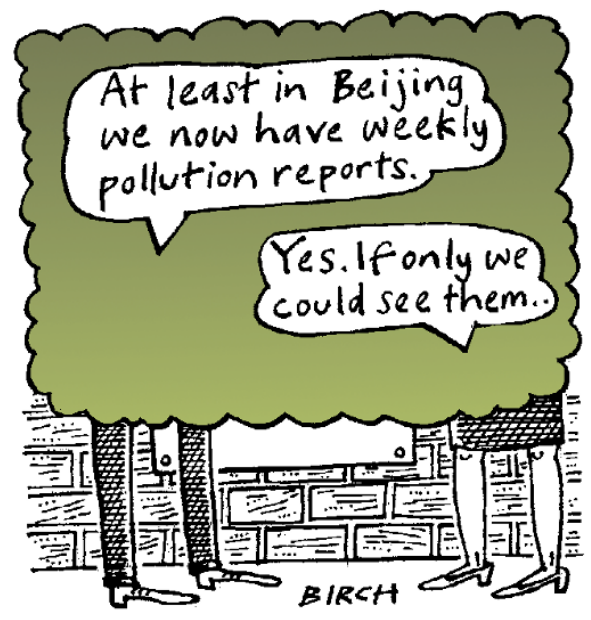

China's most progressive cities, the levels of three key pollutants — sulphur dioxide, nitrous oxides and total suspended particulates - are released each week. But in Beijing, only the level of the worst pollutant among the three is announced.

Last year's World Bank report said levels of sulphur dioxide and particulates in major Chinese cities such as Beijing, Shenyang and Xiían were two to five times higher than the maximum recommended by the World Health Organization, making them among the most badly polluted cities in the world .

Among new activities in Beijing in recent weeks, the municipal environmental protection and traffic administration bureaus have begun spot checks of cars to find out if they have catalytic converters, fining drivers of the worst polluting cars.

The local Beijing authorities have also announced that they will use 1.5 billion cubic metres of natural gas over the next two years in a bid to discourage residents from burning coal bricks in home stoves. The city plans to set up 40 coal-free zones and encourage the use of high grade coal elsewhere, as well as introducing central heating to 50 per cent of homes by 2000 .

The burning of coal in homes is one of main sources of air pollution. The 27 million tons of coal that Beijing burns each year produces a haze with high levels of sulphur dioxide and dust that hangs over the city and chokes residents.

DavidSwinbanks

\section{Banned drug 'still used until this month'}

[WASHINGTON] The New York research institute recently criticized for using a nowbanned diet drug in experiments on young children has revealed that until this month the drug, fenfluramine, was still used in separate psychiatric tests with adolescents.

The study that first drew attention, nontherapeutic research into aggression in poor, young, non-white boys, was actually stopped in 1995, two years before fenfluramine part of the diet-drug combination Fen-Phen - was withdrawn from the market after evidence that it caused serious heart-valve damage in adults who used it for months (see Nature 392, 747; 1998).

But the New York State Psychiatric Institute continued a separate study using the drug until this month, with approval from the US Food and Drug Administration (FDA). Claudia Bial, a spokeswoman for the Manhattan-based institute, says that the goal of this work was "to determine if adolescents with major depressive disorder, and who attempt suicide, show evidence of abnormal brain-serotonin function".

Fenfluramine increases brain serotonin levels. Bial says that the study, funded by the National Institute of Mental Health, was begun in 1992, and had enrolled 98 subjects before it ceased temporarily when the FDA withdrew fenfluramine in September, 1997.

After researchers gained FDA permission, the study was restarted in March this year, and two more subjects received single doses of fenfluramine before the investigators stopped the study this month because of the storm unleashed by local press reports of the work on children.

The FDA defended both studies at a congressional hearing last week. While declining to comment on the scientific significance of the work, Michael Friedman, the acting FDA commissioner, said he felt it was "appropriate and ethical and that it is being conducted under carefully scrutinized circumstances". But, he added, "I can assure you that I'm going to be looking into it much more carefully."

Friedman told the House of Representatives Government Reform and Oversight Committee that after fenfluramine was recalled from clinical use as a diet drug, researchers using it were allowed to continue on three conditions: that informed consent forms were revised to reflect the risk of heart damage (parents sign these on behalf of their children); that echocardiograms of subjects' heart valves were conducted before and after the research; and that local institutional review boards consented to the research in the light of the new findings about valve damage.

Bial said these conditions were met, and provided an informed consent form for the adolescent study that warned of "potentially life-threatening ... heart-valve damage". She said that echocardiograms on the two recent subjects revealed no damage. Friedman also stressed participation in the research was "voluntary". He told committee chairman Dan Burton (Republican, Indiana) it was "a question of personal choice".

But Burton said that he could not understand the government's approval of a child's exposure to a drug whose effects in adults had proved so damaging.

Friedman said that there had "never" been a case of heart-valve damage from one dose of fenfluramine in an adult, but conceded that data on children was scant.

Adil Shamoo, of Citizens for Responsible Care in Psychiatry and Research, an advocacy group, told the hearing that the researchers had "no therapeutic or medical cause" to use fenfluramine on the youngsters.

Meredith Wadman 